\title{
Analysis, Design and Implementation of an Interleaved DC/DC Converter with Series-Connected Transformers
}

\author{
Bor-Ren $\operatorname{Lin}^{\dagger}$ and Chih-Chieh Chen * \\ ${ }^{\dagger *}$ Dept. of Electrical Eng., National Yunlin University of Science and Technology, Yunlin, Taiwan
}

\begin{abstract}
An interleaved DC/DC converter with series-connected transformers is presented to implement the features of zero voltage switching (ZVS), load current sharing and ripple current reduction. The proposed converter includes two half-bridge converter cells connected in series to reduce the voltage stress of the switches at one-half of the input voltage. The output sides of the two converter cells with interleaved pulse-width modulation are connected in parallel to reduce the ripple current at the output capacitor and to achieve load current sharing. Therefore, the size of the output chokes and the capacitor can be reduced. The output capacitances of the MOSFETs and the resonant inductances are resonant at the transition instant to achieve ZVS turn-on. In addition, the switching losses on the power switches are reduced. Finally, experiments on a laboratory prototype (24V/40A) are provided to demonstrate the performance of the proposed converter.
\end{abstract}

Key words: DC Converter, Soft Switching.

\section{INTRODUCTION}

Power factor correction (PFC) schemes have been widely used in the front stage to reduce reactive power reduction and to eliminate line current harmonics at the utility side. For a three-phase 380V PFC converter, the DC bus voltage may be higher than $600 \mathrm{~V}$. Therefore, MOSFETs with $600 \mathrm{~V}$ of voltage stress cannot be adopted in the second stage DC/DC converter. To overcome this voltage limitation of MOSFETs, three-level DC/DC converters [1]-[4] have been proposed with more power switches, split capacitors and clamp diodes. Thus the voltage stress of the MOSFETs can be reduced to one-half of the DC bus voltage so that high frequency MOSFETs with $600 \mathrm{~V}$ of voltage stress can be used in second stage DC/DC converters. However, the main drawbacks of three-level converters are their complicated control schemes and high circuit costs. In addition, high circuit efficiency and high power density are demanded for modern switching mode power supplies. To achieve high circuit efficiency, light weight and a compact size, power converters with

Manuscript received Jan. 5, 2012; revised May 2, 2012

Recommended for publication by Associate Editor Honnyong Cha.

${ }^{\dagger}$ Corresponding Author: linbr@yuntech.edu.tw

Tel: +886-5-5517456, Fax: +886-5-5312065, Nat'l Yunlin Univ. of Sci. and Tech.

*Dept. of Electrical Eng., National Yunlin University of Science and Technology, Taiwan soft-switching techniques [5]-[17] have been developed for more than twenty years. Active clamped converters [5]-[8], full-bridge phase-shift converters [9]-[10] and series resonant converters [11]-[13] have been developed to achieve zero voltage switching (ZVS) turn-on for switches. The active-clamping topology is one kind of soft switching technique to achieve ZVS turn-on by utilizing the energy stored in the leakage and magnetizing inductances. Thus the voltage rating of the power switch is clamped to the input voltage and the clamping capacitor voltage. Full-bridge phase-shift converters can achieve soft switching for power switches with a PWM phase shift between the leading and lagging legs. However, it is difficult to realize ZVS turn-on in wide load ranges for MOSFETs in the lagging leg due to the limited energy in the leakage inductance. Resonant converters can regulate the output voltage and realize ZVS turn-on with a variable switching frequency. Although the switches can be turned on with zero voltage switching (ZVS), the disadvantages of the resonant converters are a variable switching frequency and high voltage or current stresses on the power semiconductors. This is especially true for high voltage or high current applications. Asymmetrical pulse-width modulation (PWM) [14]-[15] has been proposed to realize the magnetizing flux reset. Thus the voltage spike on power MOSFETs can be reduced to a safety region. 
This paper presents an interleaved DC/DC converter for high input voltage applications. The main advantages of the proposed converter are low switching losses, ZVS turn-on, low voltage stress on the MOSFETs and less ripple current at the output side. Two capacitors and two half-bridge converters are connected in series in the primary side to reduce the voltage stress of the MOSFETs at one-half of the DC bus voltage. The two converter cells are operated with interleaved PWM to reduce the output ripple current. Thus the size of the output chokes and the output capacitor can be reduced. For each of the converter cells, there are two asymmetric half-bridge circuit cells with the same MOSFETs to regulate the output voltage at a desired voltage level. The transformer secondary windings of the two circuits are connected in series to balance the primary winding currents. Thus the size of the transformer core and bobbin is reduced. Based on the resonant behavior by the output capacitance of the MOSFETs and the resonant inductance, the MOSFETs can be turned on under ZVS. The circuit configuration, the principle of operation, the circuit characteristics and a design example of the proposed converter are presented in detail. Experiments with a $960 \mathrm{~W}$ prototype are presented to verify the effectiveness of the proposed converter.

\section{CIRCUIT CONFIGURATION}

Fig. 1 gives the circuit configuration of the proposed interleaved DC/DC converter. The input DC bus voltage is obtained from a three-phase $380 \mathrm{~V}$ AC utility voltage with a diode rectifier. The normal DC input voltage $V_{i n}=480 \mathrm{~V} \sim 600 \mathrm{~V}$. Two input voltages and two half-bridge circuits are connected in series at the high voltage side to reduce the voltage stress of each switch at one half of the DC bus voltage. The output sides of the two half-bridge circuits are connected in parallel to reduce the current rating of the transformer windings and to share the load current. The interleaved PWM scheme is adopted to control the two half-bridge circuits so that the ripple currents of the output inductors are partially cancelled and the size of the output magnetic core is decreased. There are several ways to solve the problem of balancing two input capacitor voltages. Two capacitor voltages can be balanced by a PFC converter with two output voltage balance control or by adding a balanced resistor parallel to each of the input capacitors. Parallel balanced resistors are mostly used in UPS systems with a half-bridge inverter. The components of circuit 1 include $V_{i n 1}, S_{1}, S_{2}, C_{r 1}, C_{r 2}, C_{1}, C_{2}, L_{r 1}, L_{r 2}, T_{1}$, $T_{2}, D_{1}, D_{2}$ and $L_{o 1}$. Similarly, the components of circuit 2 include $V_{i n 2}, S_{3}, S_{4}, C_{r 3}, C_{r 4}, C_{3}, C_{4}, L_{r 3}, L_{r 4}, T_{3}, T_{4}, D_{3}, D_{4}$ and $L_{o 2} . C_{o}$ and $R_{o}$ denote the output capacitance and the load resistance. $C_{1} \sim C_{4}$ are the DC blocking capacitances. The DC blocking voltages $V_{C 1} \sim V_{C 4}$ are related to the duty ratio of the active switch. $L_{r 1} \sim L_{r 4}$ are the resonant

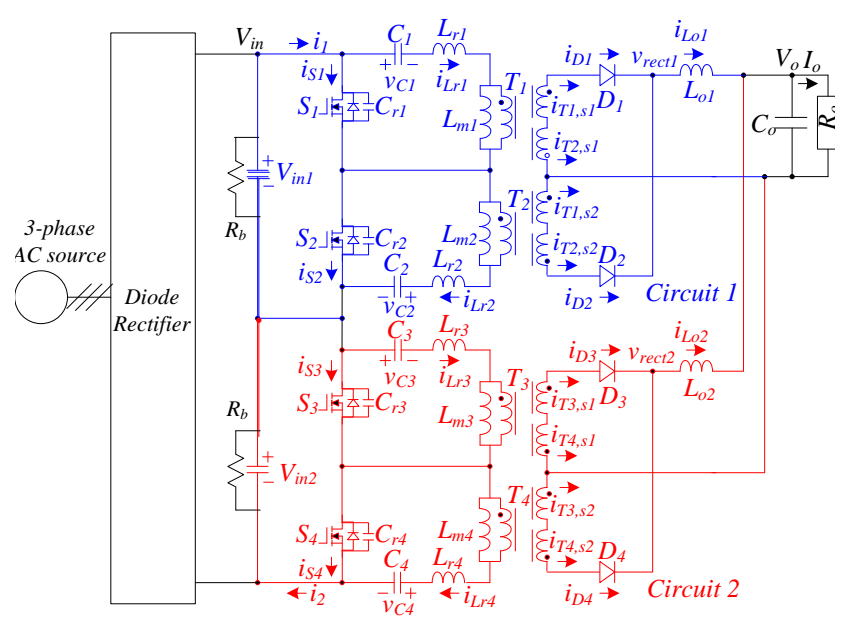

Fig. 1. Circuit configuration of the proposed interleaved converter.

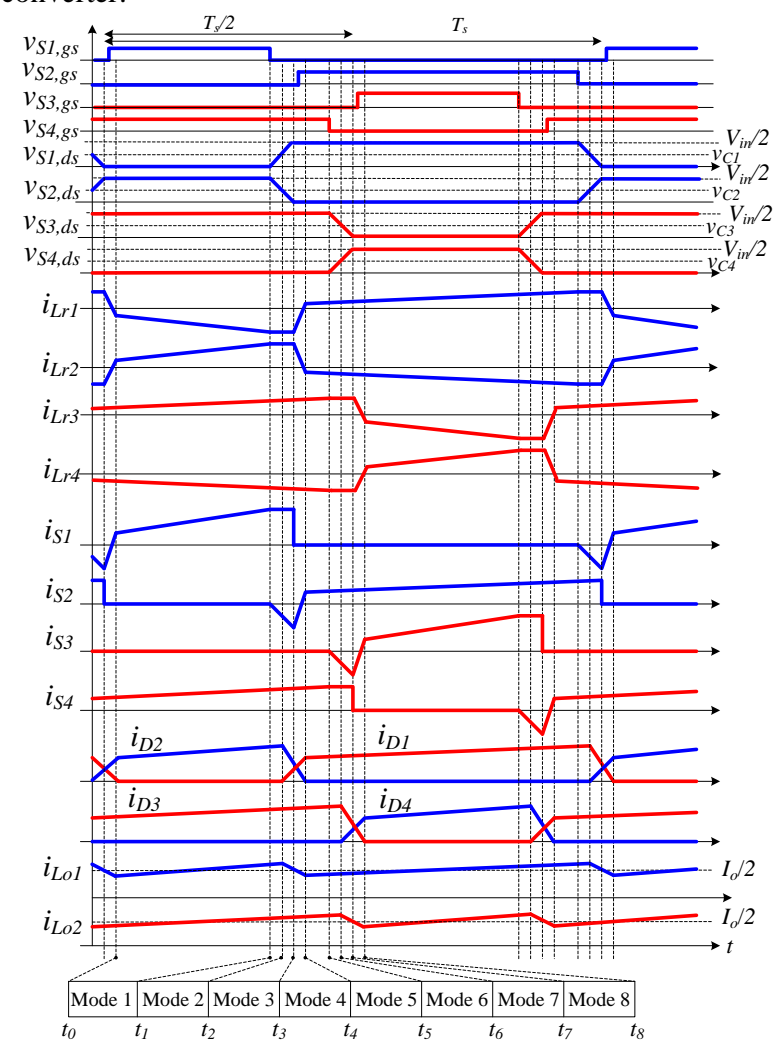

Fig. 2. Key waveforms of the proposed converter.

inductances. $L_{m 1} \sim L_{m 4}$ are the magnetizing inductances of the transformers $T_{1} \sim T_{4}$, respectively. $D_{1} \sim D_{4}$ are the rectifier diodes and $L_{o 1}$ and $L_{o 2}$ are output inductances. $C_{r 1} \sim C_{r 4}$ are the output capacitances of the MOSFETs $S_{1} \sim S_{4}$, respectively. To balance the primary currents and to reduce the winding turns of $T_{1}$ and $T_{2}$, the secondary windings of $T_{1}$ and $T_{2}$ are connected in series. The voltage stress of $S_{1} \sim S_{4}$ is clamped to $V_{\text {in }} / 2$. The center-tapped rectifier is adopted to have only one diode conduction loss in the secondary side. The PWM 
signals of $S_{1}$ and $S_{3}$ are phase-shifted by about one-half of a switching period to reduce the ripple current at the output capacitor. The gate signals of $S_{1}$ and $S_{2}$ in circuit 1 are complementary to each other with a dead time to achieve asymmetric PWM operation. In the same manner, the gate signals of $S_{3}$ and $S_{4}$ in circuit 2 are also complementary. Since the asymmetric PWM scheme is used in the proposed converter, the active switches $S_{1} \sim S_{4}$ can be turned on under ZVS at the transition interval.

\section{OPERATION PRINCIPLE}

The theoretical waveforms of the proposed converter during one switching cycle are shown in Fig. 2. The duty cycles of $S_{1}$ and $S_{3}$, are $\delta$, and the duty cycles of $S_{2}$ and $S_{4}$ are $1-\delta$. Before the system analysis, the following assumptions are made:

- Input voltages $V_{\text {in } 1}=V_{\text {in2 }}=V_{\text {in }} / 2$;

- The power semiconductors $S_{1} \sim S_{4}$ and $D_{1} \sim D_{4}$ are ideal;

- $L_{m 1}=L_{m 2}=L_{m 3}=L_{m 4}=L_{m}, L_{r 1}=L_{r 2}=L_{r 3}=L_{r 4}=L_{r}<<L_{m}$ and $L_{o 1}=L_{o 2}=L_{o}$;

- Turns ratio of transformers $T_{1} \sim T_{4}$ is $n=n_{p} / n_{s}$;

- $C_{r 1}=C_{r 2}=C_{r 3}=C_{r 4}=C_{r}$ and $C_{1}=C_{2}=C_{3}=C_{4}=C_{c}>>C_{r}$;

- The energy stored in the resonant inductances $L_{r 1}$ and $L_{r 2}$ is greater than the energy stored in the resonant capacitances $C_{r 1}$ and $C_{r 2}$ so that the ZVS turn-on of the switches can be achieved.

The asymmetric PWM scheme is used to control switches $S_{1} \sim S_{4}$. The two switch signals $S_{1}$ and $S_{2}$ are complementary and have a short dead time. In the same manner, switches $S_{3}$ and $S_{4}$ are also complementary. However, the gate signals of $S_{1}$ and $S_{3}$ are phase-shifted by one-half of a switching cycle. Based on the on/off states of $S_{1} \sim S_{4}$ and $D_{1} \sim D_{4}$, there are sixteen operation modes in a switching period. Since the PWM waveforms of two circuits are symmetrical, eight

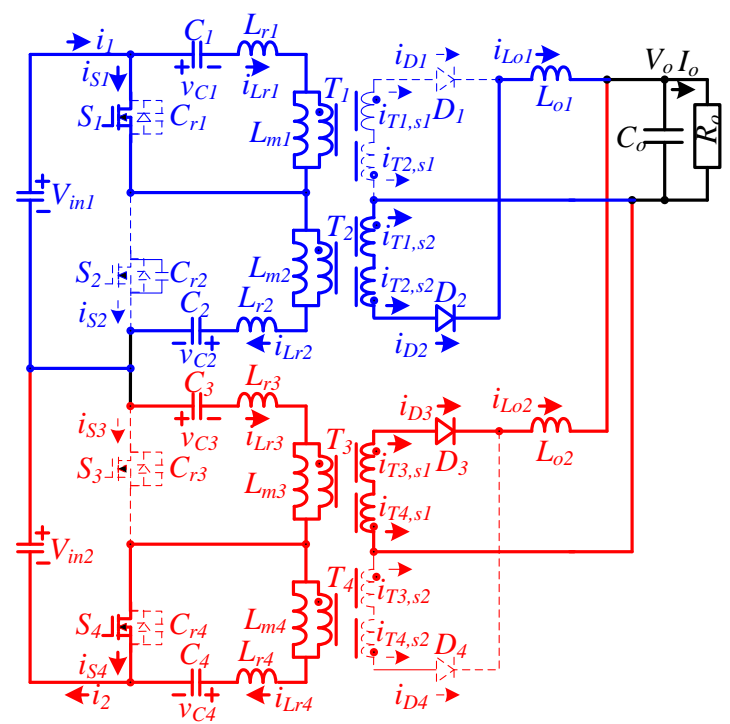

(a) operation modes in first half cycle are discussed and shown in Fig. 3. Prior to $t_{0}$, switches $S_{1}$ and $S_{4}$ are in the on-state and the rectifier diodes $D_{1} \sim D_{3}$ are conducting.

Mode $1\left[\boldsymbol{t}_{0} \leq \boldsymbol{t}<\boldsymbol{t}_{1}\right]$ : At time $t_{0}, i_{D 1}=0$. In this mode, $S_{1}$ and $S_{4}$ are in the on-state. The primary voltages $v_{L m 1} \approx-V_{C 1}<0$, $v_{L m 2} \approx V_{\text {in }} / 2-V_{C 2}>0, \quad v_{L m 3} \approx V_{\text {in }} / 2-V_{C 3}>0$ and $v_{L m 4} \approx-V_{C 4}<0$. The magnetizing currents $i_{L m 1}$ and $i_{L m 4}$ decrease and the currents $i_{L m 2}$ and $i_{L m 3}$ increase in this mode. In circuit 1 , the secondary winding voltages of $T_{1}$ and $T_{2}$ are negative and positive, respectively so that diode $D_{2}$ is forward biased. The inductor voltage $v_{L o 1}=\left(V_{i n} / 2-V_{C 2}+V_{C 1}\right) / n-V_{o}>0$ so that the inductor current $i_{L o 1}$ increases in this mode. Power is transferred from the input voltage source $V_{i n 1}$ to the output load through $S_{1}, T_{2}$, $L_{r 2}, C_{2}, D_{2}$, and $L_{o 1}$. In circuit 2, the inductor voltage $v_{L o 2}=\left(V_{\text {in }} / 2-V_{C 3}+V_{C 4}\right) / n-V_{o}>0$ so that the inductor current $i_{L o 2}$ increases in this mode. Power is transferred from $V_{\text {in2 }}$ to the output load through $C_{3}, L_{r 3}, T_{3}, S_{4}, D_{3}$ and $L_{o 2}$. This mode ends at time $t_{1}$, when $S_{1}$ is turned off.

Mode 2 [ $\left.t_{1} \leq t<t_{2}\right]$ : At time $t_{1}, S_{1}$ is turned off. Since $i_{L r 2}-i_{L r 1}>0, C_{r 1}$ and $C_{r 2}$ are charged and discharged, respectively in this mode. Because $C_{r 1}$ and $C_{r 2}<<C_{1}$ and $C_{2}$, $v_{C r 1}$ and $v_{C r 2}$ are approximately given as:

In this mode, $i_{L r 1}$ and $i_{L r 2}$ are almost constant. The operation behavior of circuit 2 in this mode is the same as the operation in mode 1 . This mode ends at time $t_{2}$, when $v_{C r 1}=V_{C 1}$ and $v_{C r 2}=V_{C 2}$.

Mode $3\left[\boldsymbol{t}_{2} \leq \boldsymbol{t}<\boldsymbol{t}_{3}\right]$ : At time $t_{2}$, the capacitor voltages $v_{C r 1}=V_{C 1}$ and $v_{\mathrm{Cr} 2}=V_{\mathrm{C} 2}$. At this instant, the primary and secondary winding voltages of transformers $T_{1}$ and $T_{2}$ are zero voltage. Thus diodes $D_{1}$ and $D_{2}$ are conducting to commutate the inductor current $i_{L o 1}$. The output inductor voltage $v_{L o 1}=-V_{o}$ so that the inductor current $i_{L o 1}$ decreases. The diode current $i_{D 1}$ increases and the diode current $i_{D 2}$ decreases. Capacitors $C_{r 1}$ and $C_{r 2}$ are continuously charged and discharged in this mode.

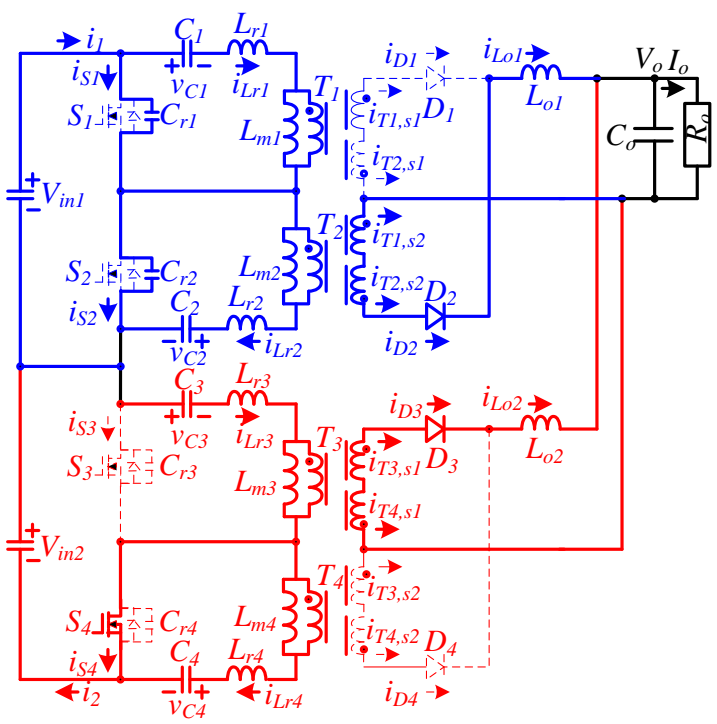

(b) 


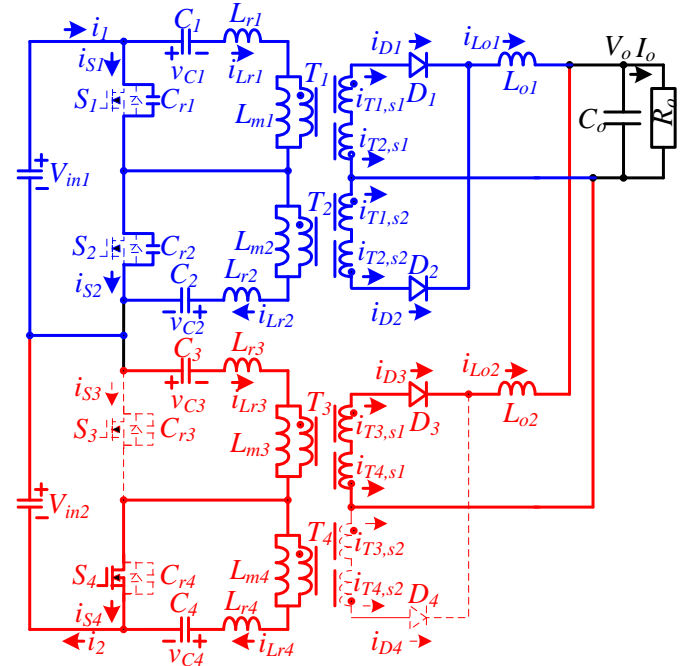

(c)

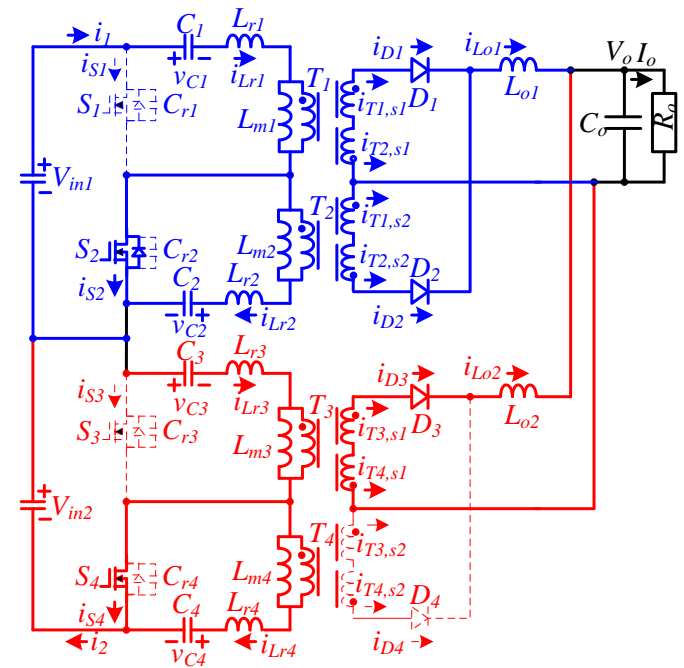

(d)

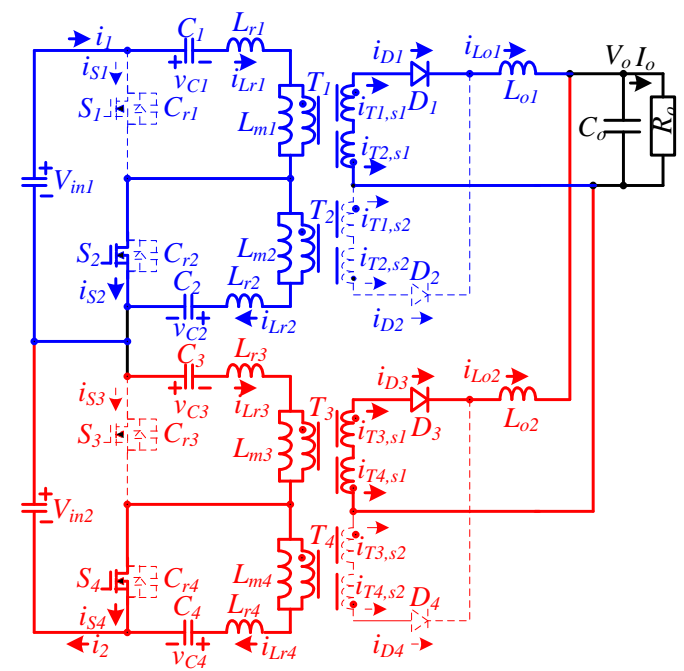

(e)

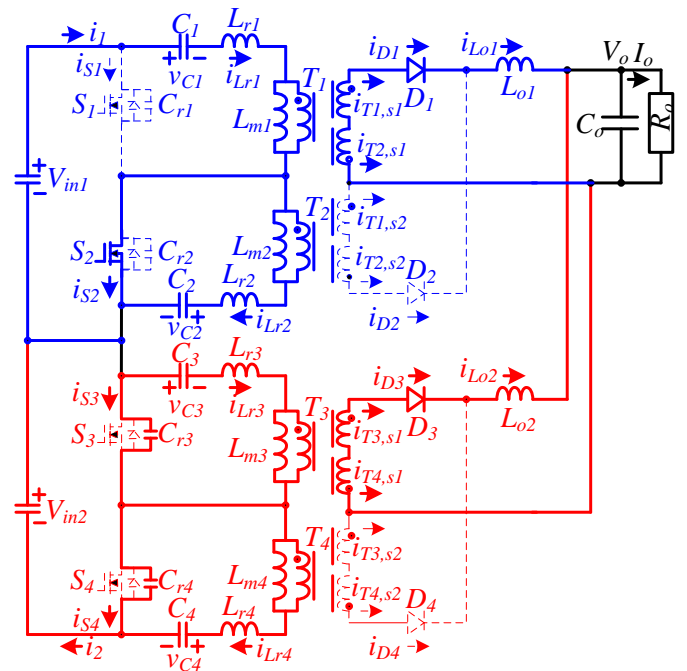

(f)

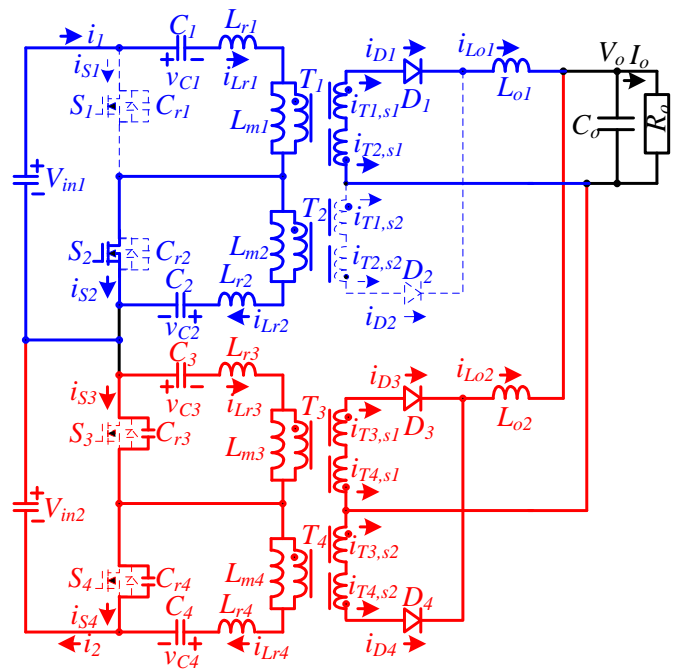

(g)

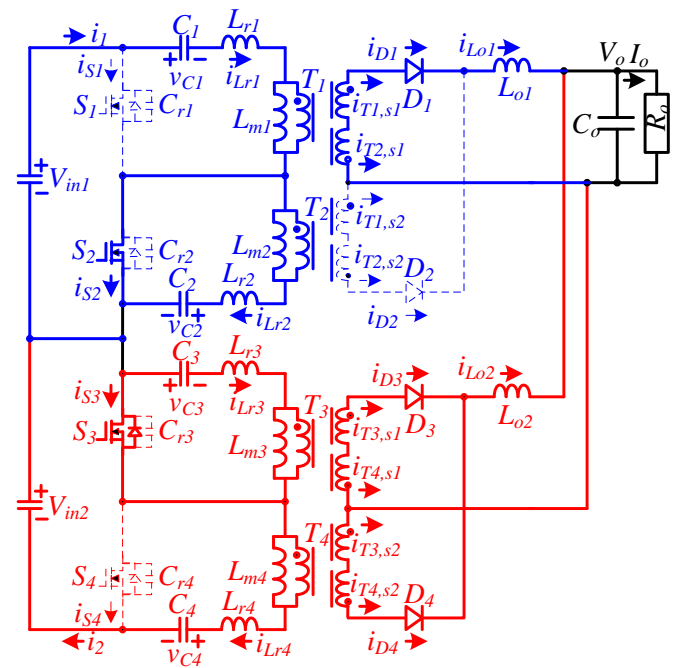

(h)

Fig. 3. Operation modes of the proposed converter during first half of switching cycle (a) mode 1 (b) mode 2 (c) mode 3 (d) mode 4 (e) mode 5 (f) mode 6 (g) mode 7 (h) mode 8. 


$$
\begin{aligned}
& v_{C r 1}(t) \approx V_{C 1}+\frac{i_{L r 2}\left(t_{2}\right)-i_{L r 1}\left(t_{2}\right)}{2 C_{r}}\left(t-t_{2}\right), \\
& v_{C r 2}(t) \approx V_{C 2}-\frac{i_{L r 2}\left(t_{2}\right)-i_{L r 1}\left(t_{2}\right)}{2 C_{r}}\left(t-t_{2}\right)
\end{aligned}
$$

If the energy stored in $L_{r 1}$ and $L_{r 2}$ is greater than the energy stored in $C_{r 1}$ and $C_{r 2}$, then $C_{r 2}$ can be discharged to zero voltage. This mode ends at time $t_{3}$, when $v_{C r 2}=0$. Then the anti-parallel diode of $S_{2}$ conducts. The time interval in modes 2 and 3 is expressed as:

$$
\Delta t_{13}=t_{3}-t_{1} \approx \frac{C_{r} V_{i n}}{i_{L r 2}\left(t_{1}\right)-i_{L r 1}\left(t_{1}\right)}
$$

In order to achieve ZVS turn-on for switch $S_{2}$, the dead time $t_{d}$ between switches $S_{1}$ and $S_{2}$ must be greater than the time interval $\Delta t_{13}$.

Mode $4 \quad\left[\boldsymbol{t}_{3} \leq \boldsymbol{t}<\boldsymbol{t}_{\mathbf{4}}\right]$ : At time $t_{3}, v_{\mathrm{Cr} 2}=0$. Since $i_{S 2}\left(t_{2}\right)=i_{L r 1}\left(t_{2}\right)-i_{L r 2}\left(t_{2}\right)<0$, the anti-parallel diode of $S_{2}$ is conducting. Before the switch current $i_{S 2}$ becomes positive, $S_{2}$ can be turned on under ZVS. Since $D_{1}$ and $D_{2}$ in the secondary side are still in the commutation interval, the resonant inductor voltages $v_{L r 1}=V_{\text {in }} / 2-V_{C 1}$ and $v_{L r 2}=-V_{C 2}$. Thus $i_{L r 1}$ increases and $i_{L r 2}$ decreases in this mode. This mode ends at time $t_{4}$ when diode current $i_{D 2}=0$. If the load current $I_{o}$ is equally supplied from two circuits, then the inductor current variation $\Delta i_{L r 1}$ in this mode is approximately equal to $I_{o} / n$. The time interval in this mode is given as:

$$
\Delta t_{34}=t_{4}-t_{3} \approx \frac{L_{r} I_{o}}{n\left(V_{\text {in }} / 2-V_{C 1}\right)}
$$

In this mode, switch $S_{2}$ is in the on-state and the inductor voltage $v_{L o 1}=-V_{o}$. No power is delivered from $V_{\text {in } 1}$ to the output load. Thus the duty loss of circuit 1 in this mode is given as:

$$
\delta_{\text {loss }, 4}=\frac{\Delta t_{34}}{T_{s}} \approx \frac{L_{r} I_{o} f_{s}}{n\left(V_{\text {in }} / 2-V_{C 1}\right)}
$$

where $T_{s}$ and $f_{s}$ are the switching period and the switching frequency, respectively.

Mode 5 [ $\boldsymbol{t}_{4} \leq \boldsymbol{t}<\boldsymbol{t}_{5}$ ]: At time $t_{4}, i_{D 2}=0$ and $D_{2}$ is turned off. The magnetizing voltages $\quad v_{L m 1} \approx V_{\text {in }} / 2-V_{C 1}>0, \quad v_{L m 2} \approx-V_{C 2}<0$, $v_{L m 3} \approx V_{\text {in }} / 2-V_{C 3}>0$ and $v_{L m 4} \approx-V_{C 4}<0$. Therefore, the magnetizing currents $i_{L m 1}$ and $i_{L m 3}$ increase and the magnetizing currents $i_{L m 2}$ and $i_{L m 4}$ decrease in this mode. The output inductor voltages $v_{L o 1}=\left(V_{i n} / 2-V_{C 1}+V_{C 2}\right) / n-V_{o}>0$ and $v_{L o 2}=\left(V_{\text {in }} / 2-V_{C 3}+V_{C 4}\right) / n-V_{o}>0$. Thus the inductor currents $i_{L o 1}$ and $i_{L o 2}$ increase in this mode. Power is transferred from $V_{i n 1}$ to the output load through $C_{1}, L_{r 1}, T_{1}, S_{2}, D_{1}$ and $L_{o 1}$ in circuit 1 . In the same manner, power is transferred from $V_{\text {in2 }}$ to the output load through $C_{3}, L_{r 3}, T_{3}, S_{4}, D_{3}$ and $L_{o 2}$ in circuit 2. This mode ends at time $t_{5}$, when switch $S_{4}$ is turned off.

Mode 6 [ $\left.\boldsymbol{t}_{5} \leq \boldsymbol{t}<\boldsymbol{t}_{6}\right]$ : At time $t_{5}, S_{4}$ is turned off. Since $i_{L r 3}\left(t_{5}\right)-i_{L r 4}\left(t_{5}\right)>0$, capacitors $C_{r 3}$ and $C_{r 4}$ are discharged and charged, respectively. The capacitor voltages $v_{C r 3}$ and $v_{C r 4}$ are approximately expressed as:

$$
\begin{aligned}
& v_{C r 3}(t) \approx \frac{V_{i n}}{2}-\frac{i_{L r 3}\left(t_{5}\right)-i_{L r 4}\left(t_{5}\right)}{2 C_{r}}\left(t-t_{5}\right), \\
& v_{C r 4}(t) \approx \frac{i_{L r 3}\left(t_{5}\right)-i_{L r 4}\left(t_{5}\right)}{2 C_{r}}\left(t-t_{5}\right)
\end{aligned}
$$

The inductor currents $i_{L r 3}$ and $i_{L r 4}$ are almost constant in this mode. This mode ends at time $t_{6}$, when $v_{C r 3}=V_{C 3}$ and $v_{\text {Cr4 }}=V_{C 4}$.

Mode $7\left[\boldsymbol{t}_{6} \leq \boldsymbol{t}<\boldsymbol{t}_{7}\right]$ : At time $t_{6}, v_{C r 3}=V_{C 3}$ and $v_{C r 4}=V_{C 4}$. The primary and secondary winding voltages of $T_{3}$ and $T_{4}$ are equal to zero voltage. Thus diodes $D_{3}$ and $D_{4}$ are both conducting to commutate the inductor current $i_{L o 2}$ and the output inductor voltage $v_{L o 2}=-V_{o}$. The inductor current $i_{L o 2}$ decreases. The diode current $i_{D 3}$ decreases and $i_{D 4}$ increases. The capacitor voltages $v_{C r 3}$ and $v_{C r 4}$ in this mode are approximately expressed as:

$$
\begin{gathered}
v_{C r 3}(t) \approx V_{C 3}-\frac{i_{L r 3}\left(t_{6}\right)-i_{L r 4}\left(t_{6}\right)}{2 C_{r}}\left(t-t_{6}\right), \\
v_{C r 4}(t) \approx V_{C 4}+\frac{i_{L r 3}\left(t_{6}\right)-i_{L r 4}\left(t_{6}\right)}{2 C_{r}}\left(t-t_{6}\right)
\end{gathered}
$$

If the energy stored in $L_{r 3}$ and $L_{r 4}$ is greater than the energy stored in $C_{r 3}$ and $C_{r 4}$, then $C_{r 3}$ can be discharged to zero voltage. This mode ends at time $t_{7}$, when $v_{C r 3}=0$. The time interval in modes 6 and 7 are expressed as:

$$
\Delta t_{57}=t_{7}-t_{5} \approx \frac{C_{r} V_{i n}}{i_{L r 3}\left(t_{5}\right)-i_{L r 4}\left(t_{5}\right)}
$$

In order to turn on $S_{3}$ under ZVS, the dead time $t_{d}$ between switches $S_{3}$ and $S_{4}$ must be greater than the time interval $\Delta t_{57}$.

Mode $8 \quad\left[\boldsymbol{t}_{7} \leq \mathbf{t}<\boldsymbol{t}_{8}\right]:$ At time $t_{7}, v_{C r 3}=0$. Since $i_{S 3}\left(t_{7}\right)=i_{L r 4}\left(t_{7}\right)-i_{L r 3}\left(t_{7}\right)<0$, the anti-parallel diode of $S_{3}$ is conducting. Before $i_{S 3}$ is positive, switch $S_{3}$ can be turned on under ZVS. In this mode, diodes $D_{3}$ and $D_{4}$ in circuit 2 are still in the commutation state. The inductor voltages $v_{L r 3}=-V_{C 3}$ and $v_{L r 4}=V_{i n} / 2-V_{C 4}$. Thus the inductor current $i_{L r 1}$ decreases and $i_{L r 2}$ increases. This mode ends at time $t_{8}$, when the diode current $i_{D 3}=0$. The inductor current variation $\Delta i_{L r 3}$ is approximately equal to $I_{o} / n$. The time interval in this mode is given as:

$$
\Delta t_{78}=t_{8}-t_{7} \approx \frac{L_{r} I_{o}}{n V_{C 3}}
$$

In this mode, switch $S_{3}$ is in the on-state and the output inductor voltage $v_{L o 2}=-V_{o}$. Thus the duty loss of circuit 2 in this mode is given as:

$$
\delta_{\text {loss }, 8}=\frac{\Delta t_{78}}{T_{s}} \approx \frac{L_{r} I_{o} f_{s}}{n V_{C 3}}
$$

The operating modes of the proposed converter in the first half of a switching cycle are complete. The operation modes 9-16 of circuit 1 are symmetrical to the operation modes 1-8 of circuit 2. In the same manner, the operation modes 9-16 of circuit 2 are symmetrical to the operation modes 1-8 of circuit 1. 


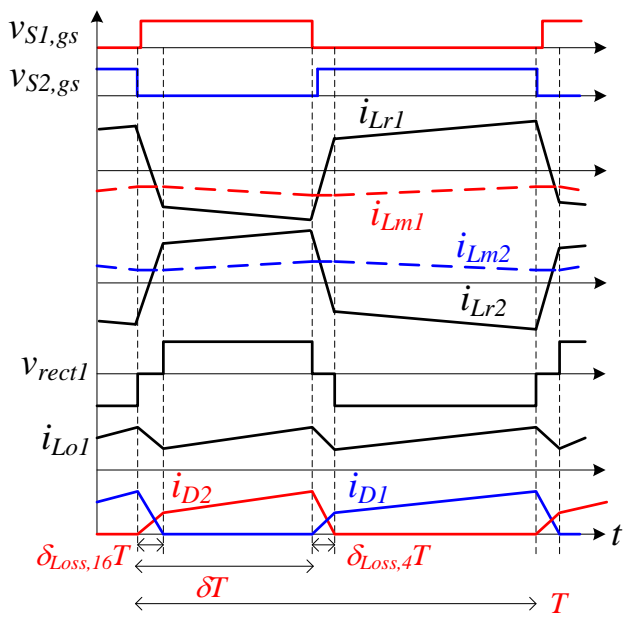

Fig. 4. Main key waveforms of the simplify main operation modes in converter 1 .

\section{CIRCUIT CHARACTERISTICS}

Since the transition intervals at the turn-on and turn-off instants are much less than the turn-on time of the power switches, the transition intervals at modes $2,3,6,7,10,11$, 14 and 15 are neglected in the analysis of the circuit characteristics. However, the effect of the duty cycle losses at modes 4, 8, 12 and 16 needs to be considered when the switch is in the on-state and the rectifier diodes at the secondary side are in the commutation mode. Fig 4 shows the main four operating modes in the circuit during one switching cycle. From the volt-second balance on the primary windings of $T_{1} \sim T_{4}$, the capacitor voltages $V_{C 1} \sim V_{C 4}$ are expressed as:

$$
V_{C 1}=V_{C 3}=\frac{(1-\delta) V_{i n}}{2}, \quad V_{C 2}=V_{C 4}=\frac{\delta V_{i n}}{2}
$$

where $\delta$ is the duty cycle of $S_{1}$ and $S_{3}$. Based on the key waveforms shown in Fig. 4 and the voltage-second balance on the output inductor $L_{o 1}$ at steady state, the DC voltage conversion ratio of the proposed converter can be obtained.

$$
\frac{V_{o}+V_{f}}{V_{\text {in }}}=\frac{2 \delta-2 \delta^{2}+\delta\left(\delta_{\text {loss }, 16}-\delta_{\text {loss }, 4}\right)-\delta_{\text {loss }, 16}}{n}
$$

where $V_{f}$ is the voltage drop on diodes $D_{1} \sim D_{4}$. Since $\delta_{\text {loss }, 8}=\delta_{\text {loss }, 16}$, the final output voltage of the proposed converter can be obtained from (5) and (10)-(12).

$$
V_{o}=\frac{2 V_{i n}}{n}\left[\delta(1-\delta)-\frac{2 L_{r} I_{o} f_{s}}{n V_{\text {in }}}\right]-V_{f}
$$

From (13), the output voltage $V_{o}$ is related to the duty cycle $\delta$, the input voltage $V_{i n}$, the switching frequency $f_{s}$, the resonant inductance $L_{r}$ and the load current $I_{o}$. In the steady state, the average output inductor currents $I_{L o 1}=I_{L o 2}=I_{o} / 2$. The ripple currents on output inductors can be expressed as:

$$
\Delta i_{L o 1}=\Delta i_{L o 2} \approx \frac{V_{o} \delta_{\text {loss }, 4} T_{s}}{L_{o}}=\frac{2 V_{o} L_{r} I_{o}}{n \delta V_{\text {in }} L_{o}}
$$

The peak currents of $L_{o 1}$ and $L_{o 2}$ are given as:

$$
i_{L o 1, \max }=i_{L o 2, \max }=\frac{I_{o}}{2}+\frac{V_{o} L_{r} I_{o}}{n \delta V_{i n} L_{o}}
$$

Since the average currents on capacitors $C_{1} \sim C_{4}$ are zero, the average magnetizing currents $I_{L m, T 1} \sim I_{L m, T 4}$ are obtained as:

$I_{L m, T 1}=I_{L m, T 3} \approx(2 \delta-1) I_{o} /(2 n), I_{L m, T 2}=I_{L m, T 4} \approx(1-2 \delta) I_{o} /(2 n)$

The ripple currents of $L_{m 1} \sim L_{m 4}$ can be expressed as:

$$
\Delta i_{L m} \approx \frac{V_{C 1}\left(\delta-\delta_{\text {loss }, 16}\right) T_{s}}{L_{m}}=\frac{\delta(1-\delta) V_{i n} T_{s}}{2 L_{m}}-\frac{L_{r} I_{o}}{n L_{m}}
$$

Thus the maximum magnetizing currents can be obtained from (16) and (17).

$$
\begin{gathered}
i_{L m 1, \text { max }}=i_{L m 3, \max }=\frac{(2 \delta-1) I_{o}}{2 n}+\frac{\delta(1-\delta) V_{i n} T_{s}}{4 L_{m}}-\frac{L_{r} I_{o}}{2 n L_{m}}, \\
i_{L m 2, \text { max }}=i_{L m 4, \text { max }}=\frac{(1-2 \delta) I_{o}}{2 n}+\frac{\delta(1-\delta) V_{i n} T_{s}}{4 L_{m}}-\frac{L_{r} I_{o}}{2 n L_{m}}(18)
\end{gathered}
$$

The average and root-mean-square (rms) currents on the rectifier diodes $D_{1} \sim D_{4}$ are expressed as:

$$
\begin{gathered}
I_{D 1, \mathrm{av}}=I_{D 3, a v} \approx(1-\delta) I_{o} / 2, I_{D 2, \mathrm{av}}=I_{D 4, a v} \approx \delta I_{o} / 2, \\
i_{D 1, \mathrm{rms}}=i_{D 3, \mathrm{rms}} \approx \frac{I_{o}}{2} \sqrt{1-\delta}, i_{D 2, \mathrm{rms}}=i_{D 4, \mathrm{rms}} \approx \frac{I_{o}}{2} \sqrt{\delta}(19)
\end{gathered}
$$

In modes 1 and 5 , the voltage stresses of rectifier diodes $D_{1} \sim D_{4}$ can be expressed as:

$$
\begin{aligned}
& v_{D 1, \text { stress }}=v_{D 3, \text { stress }} \approx 2(1-\delta) V_{i n} / n, \\
& v_{D 2, \text { stress }}=v_{D 4, \text { stress }} \approx 2 \delta V_{i n} / n
\end{aligned}
$$

The peak current of switch $S_{1}$ at time $t_{1}$ is approximately expressed as:

$$
\begin{aligned}
& i_{\text {S1, peak }}=i_{\text {S3, peak }} \approx i_{L r 2 \text {,max }}-i_{L r 1 \text {, min }} \\
& \approx \frac{I_{o}}{n}+\frac{2 V_{o} L_{r} I_{o}}{n^{2} \delta V_{\text {in }} L_{o}}+\frac{(1-2 \delta) I_{o}}{n}+\frac{\delta(1-\delta) V_{i n} T_{S}}{2 L_{m}}-\frac{L_{r} I_{o}}{n L_{m}}
\end{aligned}
$$

Similarly, the peak currents of $S_{2}$ and $S_{4}$ are expressed as:

$$
\begin{aligned}
& i_{S 2, \text { peak }}=i_{S 4, \text { pek }} \approx 2 i_{L o 1, \max } / n+i_{L m 1, \max }-i_{L m 2 \text {,min }} \\
& =\frac{I_{o}}{n}+\frac{2 V_{o} L_{r} I_{o}}{n^{2} \delta V_{i n} L_{o}}+\frac{(2 \delta-1) I_{o}}{n}+\frac{\delta(1-\delta) V_{i n} T_{s}}{2 L_{m}}-\frac{L_{r} I_{o}}{n L_{m}}
\end{aligned}
$$

The rms currents of switches $S_{1} \sim S_{4}$ can be approximately expressed as:

$$
\begin{aligned}
& i_{S 1, r m s}=i_{S 3, r m s} \approx 2(1-\delta) I_{o} \sqrt{\delta} / n, \\
& i_{S 2, r m s}=i_{S 4, r m s} \approx 2 \delta I_{o} \sqrt{1-\delta} / n
\end{aligned}
$$

The voltage stresses of $S_{1} \sim S_{4}$ are clamped at $V_{\text {in }} / 2$. At time $t_{2}$ in mode 3 , the inductor currents $i_{L r 1}\left(t_{2}\right)$ and $i_{L r 2}\left(t_{2}\right)$ are approximately given as:

$$
\begin{aligned}
& i_{L r 1}\left(t_{2}\right)=i_{L r 3}\left(t_{10}\right)=-\frac{i_{L o 1, \text { max }}}{n}+i_{L m 1, \text { min }} \\
& \approx-\frac{I_{o}}{2 n}-\frac{V_{o} L_{r} I_{o}}{n^{2} \delta V_{i n} L_{o}}+\frac{(2 \delta-1) I_{o}}{2 n}-\frac{\delta(1-\delta) V_{i n} T_{s}}{4 L_{m}}+\frac{L_{r} I_{o}}{2 n L_{m}}, \\
& i_{L r 2}\left(t_{2}\right)=i_{L r 4}\left(t_{10}\right)=\frac{i_{L o 1, \max }}{n}+i_{L m 2, \max } \\
& \approx \frac{I_{o}}{2 n}+\frac{V_{o} L_{r} I_{o}}{n^{2} \delta V_{i n} L_{o}}+\frac{(1-2 \delta) I_{o}}{2 n}+\frac{\delta(1-\delta) V_{i n} T_{s}}{4 L_{m}}-\frac{L_{r} I_{o}}{2 n L_{m}}
\end{aligned}
$$


Similarly the inductor currents $i_{L r 3}\left(t_{6}\right)$ and $i_{L r 4}\left(t_{6}\right)$ in mode 7 are approximately given as:

$$
\begin{aligned}
& i_{L r 3}\left(t_{6}\right)=i_{L r 1}\left(t_{14}\right)=\frac{i_{L o 2, \max }}{n}+i_{L m 3, \max } \\
& \approx \frac{I_{o}}{2 n}+\frac{V_{o} L_{r} I_{o}}{n^{2} \delta V_{i n} L_{o}}+\frac{(2 \delta-1) I_{o}}{2 n}+\frac{\delta(1-\delta) V_{i n} T_{s}}{4 L_{m}}-\frac{L_{r} I_{o}}{2 n L_{m}}, \\
& i_{L r 4}\left(t_{6}\right)=i_{L r 2}\left(t_{14}\right)=-\frac{i_{L o 2, \max }}{n}+i_{L m 4, \min } \\
& \approx-\frac{I_{o}}{2 n}-\frac{V_{o} L_{r} I_{o}}{n^{2} \delta V_{i n} L_{o}}+\frac{(1-2 \delta) I_{o}}{2 n}-\frac{\delta(1-\delta) V_{i n} T_{s}}{4 L_{m}}+\frac{L_{r} I_{o}}{2 n L_{m}}
\end{aligned}
$$

The ZVS conditions of $S_{1} \sim S_{4}$ are given in (26).

$$
\begin{gathered}
L_{r, S 1} \geq \frac{(1-\delta) C_{r} V_{i n}^{2}}{2\left[i_{L r 1}^{2}\left(t_{14}\right)+i_{L r 2}^{2}\left(t_{14}\right)\right]}, L_{r, S 2} \geq \frac{\delta C_{r} V_{i n}^{2}}{2\left[i_{L r 1}^{2}\left(t_{2}\right)+i_{L r 2}^{2}\left(t_{2}\right)\right]}, \\
L_{r, S 3} \geq \frac{(1-\delta) C_{r} V_{i n}^{2}}{2\left[i_{L r 3}^{2}\left(t_{6}\right)+i_{L r 4}^{2}\left(t_{6}\right)\right]}, L_{r, S 4} \geq \frac{\delta C_{r} V_{i n}^{2}}{2\left[i_{L r 3}^{2}\left(t_{10}\right)+i_{L r 4}^{2}\left(t_{10}\right)\right]}(26)
\end{gathered}
$$

Since $i_{L r 3}\left(t_{6}\right)=i_{L r 1}\left(t_{14}\right), i_{L r 4}\left(t_{6}\right)=i_{L r 2}\left(t_{14}\right), i_{L r 3}\left(t_{10}\right)=i_{L r 1}\left(t_{2}\right)$, and $i_{L r 4}\left(t_{10}\right)=i_{L r 2}\left(t_{2}\right)$, the ZVS condition of $S_{1} \sim S_{4}$ can be further expressed as:

$$
L_{r} \geq \max \left\{\frac{\delta C_{r} V_{i n}^{2}}{2\left[i_{L r 1}^{2}\left(t_{2}\right)+i_{L r 2}^{2}\left(t_{2}\right)\right]}, \frac{(1-\delta) C_{r} V_{i n}^{2}}{2\left[i_{L r 1}^{2}\left(t_{14}\right)+i_{L r 2}^{2}\left(t_{14}\right)\right]}\right\}
$$

\section{DESIGN PROCEDURE AND EXPERIMENTAL RESULTS}

A prototype circuit with the design procedure is presented in this section. The specifications of the prototype circuit are $V_{\text {in }}=480 \sim 580 \mathrm{~V}, V_{o}=24 \mathrm{~V}$, and $I_{o}=40 \mathrm{~A}$. The circuit efficiency is assumed to be $90 \%$. The switching frequency of the proposed converter is $f_{s}=100 \mathrm{kHz}$. The nominal input terminal voltage $V_{\text {in,nom }}$ is $530 \mathrm{~V}$. The maximum duty cycle of switches $S_{1}$ and $S_{3}$ is equal to 0.48 at the minimum input voltage $V_{\text {in }}=480 \mathrm{~V}$ and the full load condition. The maximum duty cycle loss in modes 4 and 16 is assumed 15\% under a full load with a duty cycle $\delta=0.5$.

$$
\delta_{\text {loss }}=\delta_{\text {loss }, 4}+\delta_{\text {loss }, 16} \approx \frac{8 I_{o} L_{r} f_{s}}{n V_{\text {in }}} \approx \frac{16 P_{o} L_{r} f_{s}}{\eta V_{\text {in }}^{2}}<0.15
$$

From (29), the resonant inductance of $L_{r}$ can be obtained as :

$$
L_{r}<\frac{\eta V_{i n, \min }^{2} \delta_{\text {loss }}}{16 P_{o} f_{s}}=\frac{0.9 \times 480^{2} \times 0.15}{16 \times 960 \times 100000} \approx 20.25 \mu \mathrm{H}
$$

The actual resonant inductance $L_{r}=18 \mu \mathrm{H}$ is used in the prototype circuit. From (13), the turns ratio of $T_{1} \sim T_{4}$ is obtained as:

$$
\begin{aligned}
& n \approx\left[\delta_{\max }\left(1-\delta_{\max }\right) V_{\text {in,min }}+\right. \\
& \sqrt{\left.\left[\delta_{\max }\left(1-\delta_{\max }\right) V_{i n, \text { min }}\right]^{2}-4\left(V_{o}+V_{f}\right) I_{o} L_{r} f_{f}\right]} \\
& /\left(V_{o}+V_{f}\right) \approx 8.315
\end{aligned}
$$

where $\mathrm{V}_{\mathrm{f}}=0.65 \mathrm{~V}$. A TDK EER-42 magnetic core with $A_{e}=1.94 \mathrm{~cm}^{2}$ was used to design the transformers $T_{1} \sim T_{4}$. The primary turns of $T_{1} \sim T_{4}$ with $\Delta B=0.2 \mathrm{~T}$ are given as:

$$
N_{p, \text { min }} \geq \frac{V_{C 1} \delta}{A_{e} \Delta B f_{s}}=\frac{\delta_{\text {max }}\left(1-\delta_{\text {max }}\right) V_{\text {in }} / 2}{A_{e} \Delta B f_{s}} \approx 15.4
$$

In the prototype circuit, the primary winding turns $n_{p}=25$ and the secondary winding turns $n_{s}=3$. It is assumed that the magnetizing ripple current on $L_{m}$ is 0.7A. The magnetizing inductacne can be obtained from (17).

$$
L_{m}=\frac{\delta_{\max }\left(1-\delta_{\max }\right) V_{i n, \min } T_{s}-\frac{2 L_{r} I_{o}}{n}}{2 \Delta i_{L m}} \approx 733^{\prime} \mu H
$$

The actual magnetizing inductance $L_{m}$ of $T_{1} \sim T_{4}$ in the prototype circuit is $750 \mu \mathrm{H}$. From (13), the minimum duty cycle at the maximum input voltage and the full load condition is obtained as:

$$
\delta_{\min }=\frac{1-\sqrt{1-\frac{2 n\left(V_{o}+V_{f}\right)}{V_{i n, \max }}-\frac{8 L_{r} I_{o} f_{s}}{n V_{i n, \max }}}}{2} \approx 0.29
$$

In (14), the ripple current on $L_{o 1}$ and $L_{o 2}$ is set to $10 \%$. Thus the output inductances $L_{o 1}$ and $L_{o 2}$ can be obtained as:

$$
L_{o} \geq \frac{2 V_{o} L_{r} I_{o}}{n \delta_{\max } V_{i n, \min } \Delta i_{L o}} \approx 9 \mu \mathrm{H}
$$

The actual output filter inductance $L_{o}=L_{o 2}=L_{o 1}=20 \mu \mathrm{H}$. Based on (19) and (20), the average currents and the voltage stresses on the rectifier diodes are given as:

$$
\begin{gathered}
I_{D 1, \mathrm{av}}=I_{D 3, a v}=\left(1-\delta_{\min }\right) I_{o} / 2=14.2 \mathrm{~A}, \\
I_{D 2, \mathrm{av}}=I_{D 4, a v}=\delta_{\max } I_{o} / 2=9.6 \mathrm{~A}, \\
v_{D 1 \text {,stress }}=v_{D 3 \text {,stress }}=2\left(1-\delta_{\min }\right) V_{\text {in,max }} / n \approx 98.8 \mathrm{~V}, \\
v_{D 2, \text { stress }}=v_{D 4, \text { stress }}=2 \delta_{\max } V_{i n, \min } / n \approx 66.8 \mathrm{~V}
\end{gathered}
$$

U30D20C diodes with $V_{R R M}=200 \mathrm{~V}$ and $I_{F}=30 \mathrm{~A}$ are used for $D_{1} \sim D_{4}$ at the secondary side. Based on (24), the rms currents and the voltage stress of $S_{1} \sim S_{4}$ are given as:

$$
\begin{array}{r}
i_{S 1, r m s}=i_{S 3, r m s} \approx 2\left(1-\delta_{\min }\right) I_{o} \sqrt{\delta_{\min }} / n \approx 3.67 \mathrm{~A}, \\
i_{S 2, r m s}=i_{S 4, r m s} \approx 2 \delta_{\text {max }} I_{o} \sqrt{1-\delta_{\max }} / n \approx 3.32 \mathrm{~A}, \\
v_{S 1, \text { stress }}=v_{S 2, \text { stress }}=v_{S 3, \text { stress }}=v_{S 4 \text {,stress }}=V_{\text {in,max }} / 2=290 \mathrm{~V}
\end{array}
$$
In the prototype circuit, IRFP460 MOSFETs with $V_{D S}=500 \mathrm{~V}$, $I_{D, \text { rms }}=20 \mathrm{~A}, R_{D S \text {,on }}=0.27 \Omega$ and $C_{o s s}=480 \mathrm{pF}$ at $25 \mathrm{~V}$ are used for switches $S_{1} \sim S_{4}$. In the proposed circuit, the power switches $S_{1} \sim S_{4}$ are desinged to have ZVS operation from $50 \%$ load to the full load condition under a nominal input voltage. The duty cycle at $50 \%$ load and the nominal input voltage can be given as:

$$
\delta_{50 \%}=\frac{1-\sqrt{1-\frac{2 n\left(V_{o}+V_{f}\right)}{V_{\text {in, nom }}}-\frac{8 L_{r} I_{o, 50 \%} f_{s}}{n V_{\text {in, nom }}}}}{2} \approx 0.3
$$

The output capacitance $C_{\text {oss }}$ of the IRFP460 MOSFETs is $480 \mathrm{pF}$ at $25 \mathrm{~V}$. The equivalent output capacitance $C_{r}$ at $V_{\text {in }}=530 \mathrm{~V}$ is given as: 


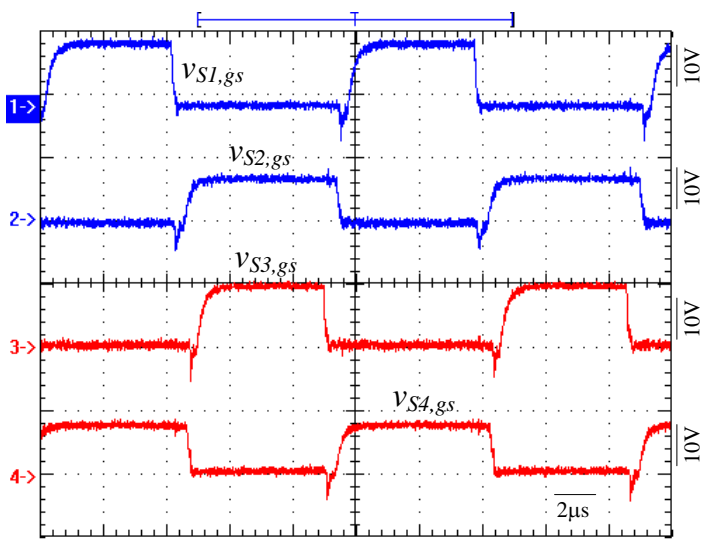

(a)

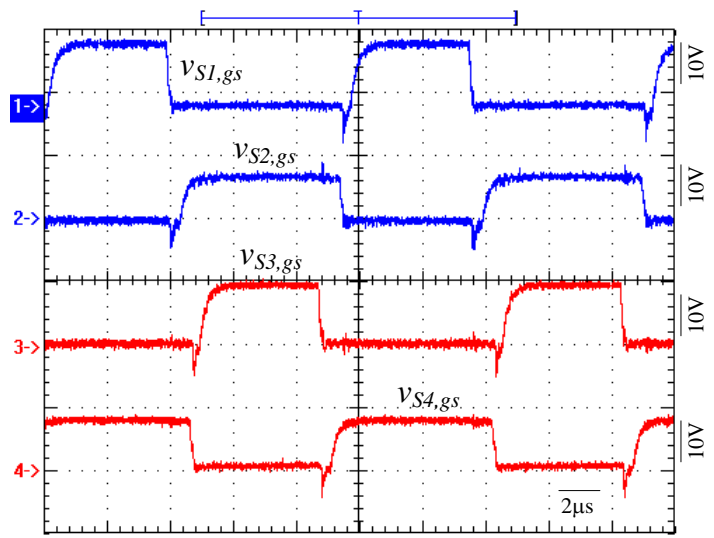

(b)

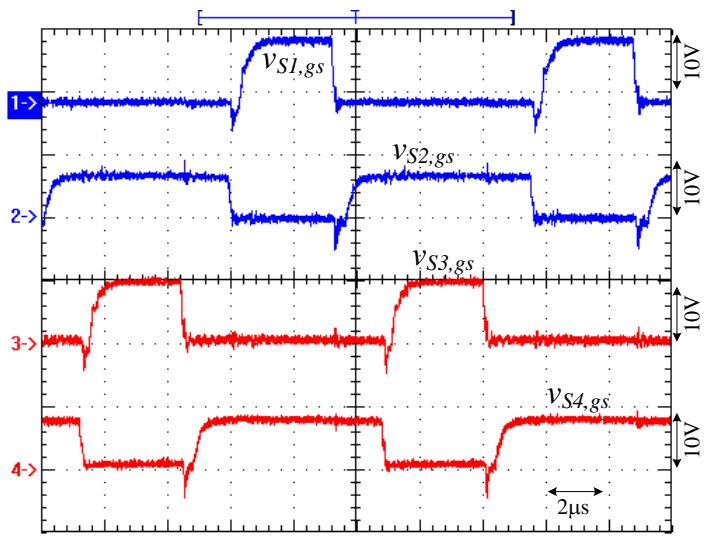

(c)

Fig. 5. Measured waveforms of the switch gate-to-source voltages at full load and (a) $V_{\text {in }}=480 \mathrm{~V}$ (b) $V_{\text {in }}=530 \mathrm{~V}$ (c) $V_{\text {in }}=580 \mathrm{~V}$.

$$
C_{r} \approx \frac{4}{3} C_{o s s, 25} \sqrt{\frac{25}{v_{S 1, d s}}}=\frac{4}{3} \times 480 \times \sqrt{\frac{25}{530 / 2}} \approx 197 p F
$$

From (24) and (25), the inductor currents $i_{L r 1}\left(t_{2}\right), i_{L r 2}\left(t_{2}\right)$, $i_{L r 1}\left(t_{14}\right)$ and $i_{L r 2}\left(t_{14}\right)$, at $50 \%$ load and $\delta_{50 \%}=0.3$ can be obtained as:

$$
\begin{gathered}
i_{L r 1}\left(t_{2}\right)=-\frac{I_{o, 50 \%}}{2 n}-\frac{V_{o} L_{r} I_{o, 50 \%}}{n^{2} \delta_{50 \%} V_{i n, n o m} L_{o}}+\frac{\left(2 \delta_{50 \%}-1\right) I_{o, 50 \%}}{2 n} \\
-\frac{\delta_{50 \%}\left(1-\delta_{50 \%}\right) V_{i n, n o m} T_{s}}{4 L_{m}}+\frac{L_{r} I_{o, 50 \%}}{2 n L_{m}} \approx-2.06 \mathrm{~A}
\end{gathered},
$$

In order to achieve ZVS of $S_{1} \sim S_{4}$ from $50 \%$ load to the full load under a nominal input voltage, the necessary resonant inductance $L_{r}$ is obtained as:

$$
L_{r} \geq \max \left\{\frac{\delta_{50 \%} C_{r} V_{i n}^{2}}{2\left[i_{L r 1}^{2}\left(t_{2}\right)+i_{L r 2}^{2}\left(t_{2}\right)\right]}, \frac{\left(1-\delta_{50 \%}\right) C_{r} V_{i n}^{2}}{2\left[i_{L r 1}^{2}\left(t_{14}\right)+i_{L r 2}^{2}\left(t_{14}\right)\right]}\right\} \approx 8 \mu \mathrm{H}
$$

From (29) and (40), the selected resonant inductor $L_{r}=18 \mu \mathrm{H}$ can meet the ZVS condition of $S_{1} \sim S_{4}$ from the $50 \%$ to the $100 \%$ load conditions. The selected capacitance of $C_{1} \sim C_{4}$ is $0.47 \mu \mathrm{F}$. The capacitance of the output capacitor $C_{o}$ is $5400 \mu \mathrm{F}$.

Experimental results with the circuit parameters derived in the previous section were provided to verify the effectiveness of the proposed converter. The measured PWM signals of $S_{1} \sim S_{4}$ under a full load and different input voltages are shown in Fig. 5. The PWM signals of $S_{1}$ and $S_{3}$ are phase-shifted by one-half of a switching cycle. Fig. 6 gives the measured gate voltage, the drain voltage and the switch current of switches $S_{1} \sim S_{4}$ under half and full loads with a nominal input voltage. The drain voltages decreased to zero before switches $S_{1} \sim S_{4}$ are turned on. Thus, $S_{1} \sim S_{4}$ are turned on under ZVS from a half load to a full load.

Fig. 7 illustrates the measured waveforms of the inductor currents $i_{L r 1} \sim i_{L r 4}$ under full load and a nominal input voltage. When switch $S_{1}$ is in the on-state, the inductor current $i_{L r 1}$ decreases and $i_{L r 2}$ increases. On the other hand, the inductor current $i_{L r 1}$ increases and $i_{L r 2}$ decreases if switch $S_{2}$ is in the on-state. Fig. 8 gives the measured waveforms of $v_{C 1}, v_{C 2}$, $v_{C 3}$ and $v_{C 4}$ under the full load condition. Fig. 9 gives the measured waveforms of $v_{S 1, g s}, i_{D 1}, i_{D 2}$ and $i_{L o 1}$ under the full load condition. Fig. 10 shows the experimental results of $i_{L o 1}$, $i_{L o 2}$ and $i_{L o 1}+i_{L o 2}$ under the full load condition. Fig. 11 shows the measured efficiencies of the proposed converter at 


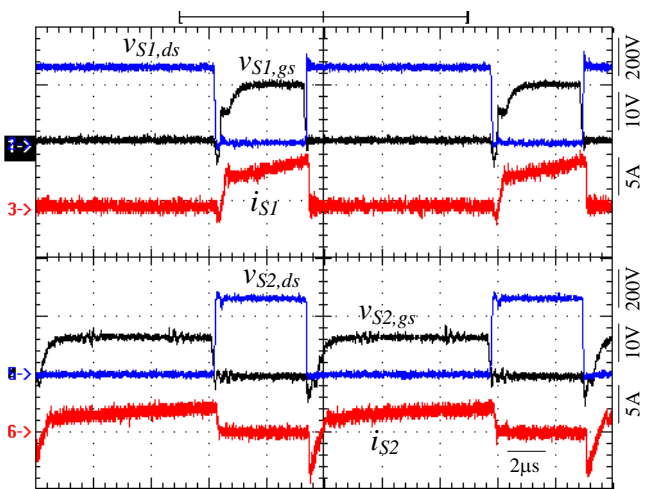

(a)

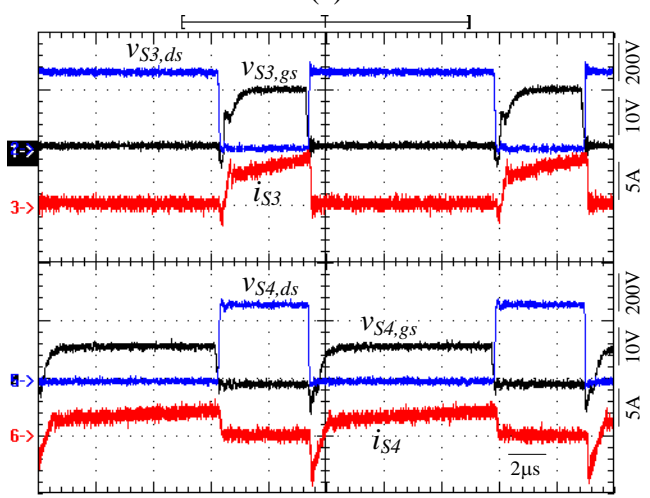

(b)

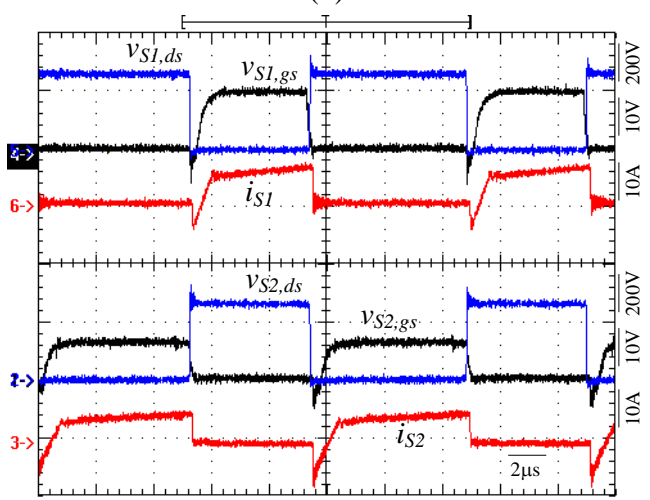

(c)

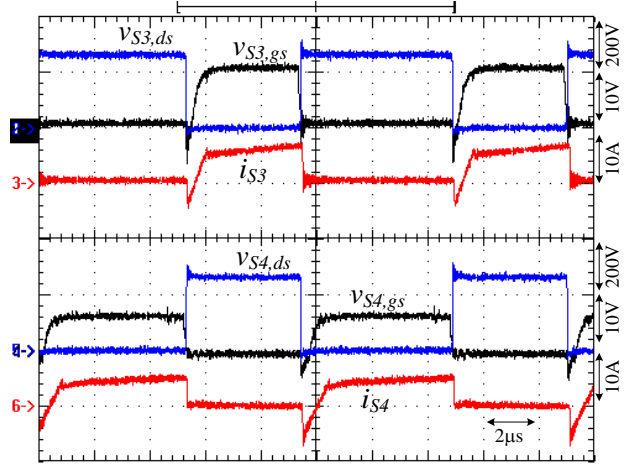

(d)

Fig. 6. Measured waveforms of the gate voltages, drain voltages and switch current at nominal input voltage $V_{\text {in }}=530 \mathrm{~V}$ and (a) $S_{1}$ and $S_{2}$ with $480 \mathrm{~W}$ load (b) $S_{3}$ and $S_{4}$ with $480 \mathrm{~W}$ load (c) $S_{1}$ and $S_{2}$ with $960 \mathrm{~W}$ load (d) $S_{3}$ and $S_{4}$ with $960 \mathrm{~W}$ load .

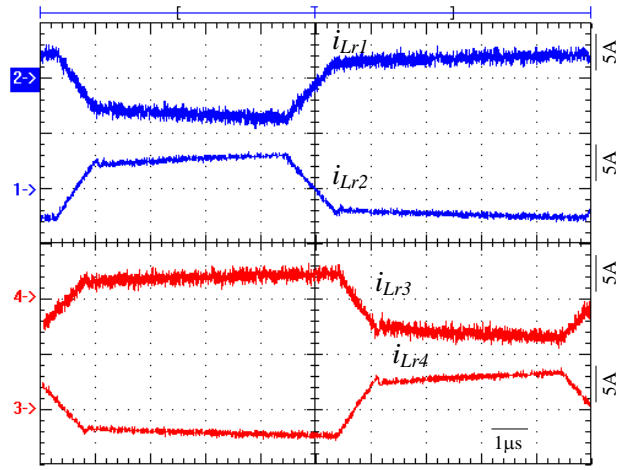

Fig. 7. Measured waveforms of inductor currents $i_{L r 1} \sim i_{L r 4}$ at full load and nominal input voltage.

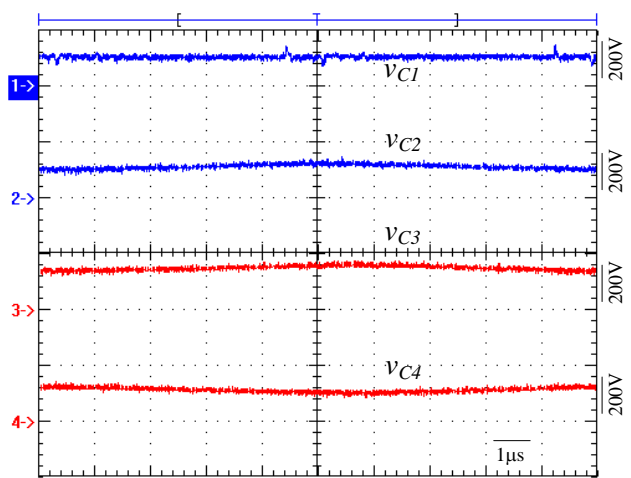

Fig. 8. Measured waveforms of $v_{C 1}, v_{C 2}, v_{C 3}$ and $v_{C 4}$ at full load condition.

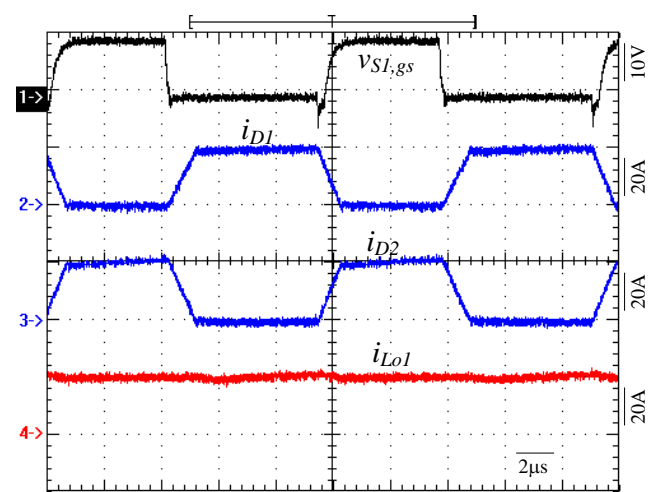

Fig. 9. Measured waveforms of $v_{S 1, g s}, i_{D 1}, i_{D 2}$ and $i_{L o 1}$ at full load condition.

\section{CONCLUSION}

An interleaved DC/DC converter with series-connected transformers is presented to achieve the following functions: 1) ZVS turn-on for all of the power switches, 2) magnetic flux reset using the asymmetric PWM scheme, 3) low voltage stress of the power switches with a series half-bridge converter, and 4) a low ripple current at the output capacitor with the interleaved PWM scheme. Two split capacitors and 


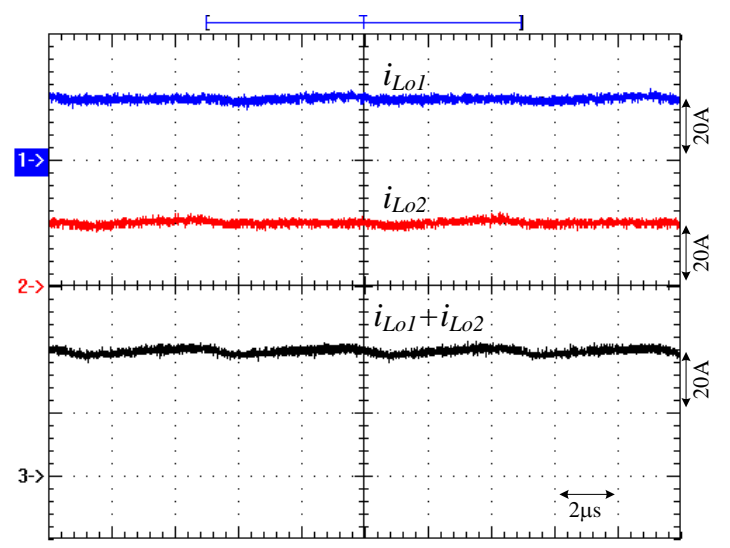

Fig. 10. Experimental results of $i_{L o 1}, i_{L o 2}$ and $i_{L o 1}+i_{L o 2}$ at full load condition.

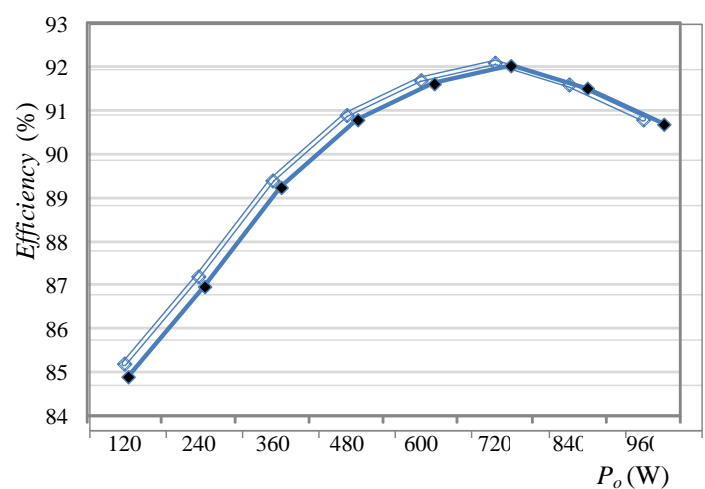

Fig. 11. Measured efficiencies of the proposed converter at different loads with nominal input voltage condition.

two half-bridge converter circuits connected in series are used in the proposed circuit to limit the voltage stress of the power switches at one-half of the input voltage. Thus the MOSFETs can be used in high input voltage applications to achieve a high switching frequency, a low converter size and a high circuit efficiency. Two half-bridge circuits are operated with the interleaved PWM scheme so that the resulting ripple current at the output capacitor can be partially cancelled. Finally, experimental results are provided to verify the effectiveness of the proposed converter.

\section{ACKNOWLEDGMENT}

The project is supported by the National Science Council of Taiwan, ROC, under Grant NSC101-2221-E-224-MY2.

\section{REFERENCES}

[1] F. Canales, P. M. Barbosa, and F. C. Lee, “A zero-voltage and zero current-switching three level DC/DC converter," IEEE Trans. Power Electron., Vol. 17, No. 6, pp. 898-904, Nov. 2002.

[2] W. Chen and X. Ruan, "Zero-voltage-switching pwm hybrid full-bridge three-level converter with secondary-voltage clamping scheme,” IEEE Trans. Ind. Electron., Vol. 55, No. 2, pp. 644-654, 2008.
[3] H. Ertl, J. W. Kolar, and F. C. Zach, "A novel multicell DC-AC converter for applications in renewable energy systems," IEEE Trans. Ind. Electron., Vol. 49, No. 5, pp. 1048-1057, Oct. 2002.

[4] H. Ertl, J. W. Kolar, and F. C. Zach, “Analysis of a multilevel multicell switch-mode power amplifier employing the flying-battery concept,” IEEE Trans. Ind. Electron., Vol. 49, No. 4, pp. 816-823, Aug. 2002.

[5] B. R. Lin, J. J. Chen, and S. F. Shen, “Zero voltage switching double-ended converter,” IET Proceedings -Power Electron., vol. 3, no. 2, pp. 187-196, Mar. 2010.

[6] S. S. Lee, S. W. Choi, and G. W. Moon, "High-efficiency active-clamp forward converter with transient current build-up (TCB) ZVS technique,” IEEE Trans. Ind. Electron., Vol. 54, No. 1, pp. 310-318, Feb. 2007.

[7] B. R. Lin and J. Y. Dong, “Analysis and implementation of an active clamping zero-voltage turn-on switching/ zero-current turn-off switching converter," IET Proceedings - Power Electron., Vol. 3, No. 3, pp. 429-437, 2010.

[8] B.-R. Lin and L.-A. Lin, "analysis and implementation of a DC-DC converter with an active snubber”, Journal of Power Electronics, Vol. 11, No. 6, pp. 779-786, Nov. 2011.

[9] J. Yungtack, M. M. Jovanovic, and Y. M. Chang, "A new ZVS-PWM full-bridge converter,” IEEE Trans. Power Electron., Vol. 18, No. 5, pp. 1122-1129, Sep. 2003.

[10] Y, Jiang, Z. Chen and J. Pan, “Zero-voltage switching phase shift full-bridge step-up converter with integrated magnetic structure,” IET Proceedings -Power Electron., Vol. 3, No. 5, pp. 732-739, 2010.

[11] K. H. Yi and G. W. Moon, "Novel two-phase interleaved LLC series-resonant converter using a phase of the resonant capacitor,” IEEE Trans. Ind. Electron., Vol. 56, No. 5, pp. 1815-1819, May 2009.

[12] X. Xie, J. Zhang, Z. Chen, Z. Zhao, and Z. Qian, “Analysis and optimization of LLC resonant converter with a novel over-current protection circuit," IEEE Trans. Power Electron., Vol. 22, No. 2, pp. 435-443, Mar. 2007.

[13] D. Fu, Y. Liu, F. C. Lee, and M. Xu, "A novel driving scheme for synchronous rectifiers in LLC resonant converters," IEEE Trans. Power Electron., Vol. 24, No. 5, pp. 1321-1329, May 2009.

[14] T. Mishima and M. Nakaoka, "A novel high-frequency transformer-linked soft-switching half-bridge DC-DC converter with constant-frequency asymmetrical PWM scheme," IEEE Trans. Ind. Electron., Vol. 56, No. 8, pp. 2961-2969, Aug. 2009.

[15] B. Choi and W. Lim, "Current-mode control to enhance closed-loop performance of asymmetrical half-bridge DC-DC converters,” IEE Proceedings - Electric Power Applications, Vol. 152, No. 2, pp. 416-422, 2005.

[16] I.-D. Kim, J.-Y. Kim, E.-C. Nho, and H.-G. Kim, “Analysis and Design of a Soft-Switched PWM Sepic DC-DC Converter," Journal of Power Electronics, Vol. 10, No. 5, pp. 461-467, Sep. 2010.

[17] J.-H. Kim, Y.-C. Jung, S.-W. Lee, T.-W. Lee, and C.-Y. Won, "Power loss analysis of interleaved soft switching boost converter for single-phase PV-PCS," Journal of Power Electronics, Vol. 10, No. 4, pp.335-341, Jul. 2010. 
Bor-Ren Lin received his B.S. in Electronic Engineering from the National Taiwan University of Science and Technology, Taipei, Taiwan, in 1988, and his M.S. and Ph.D. in Electrical Engineering from the University of Missouri, USA, in 1990 and 1993, respectively. From 1991 to 1993, he was a Research Assistant with the Power Electronic Research Center, University of Missouri. Since 1993, he has been with the Department of Electrical Engineering, National Yunlin University of Science and Technology, Douliou, Taiwan, where he is currently a Professor. He has authored more than 200 published technical journal papers in the area of power electronics. His current research interests include power-factor correction, multilevel converters, active power filters, and soft-switching converters. Dr. Lin is an Associate Editor of the IEEE Transactions on Industrial Electronics, The Institution of Engineering and Technology Proceedings-Power Electronics and the Journal of Power Electronics. He was the recipient of Research Excellence Awards in 2004, 2005, 2007 and 2011 from the College of Engineering, National Yunlin University of Science and Technology. He received best paper awards from the IEEE Conference on Industrial Electronics and Applications 2007 and 2011, from the Taiwan Power Electronics 2007 Conference, and from the IEEE Power Electronics and Drive Systems 2009 Conference.

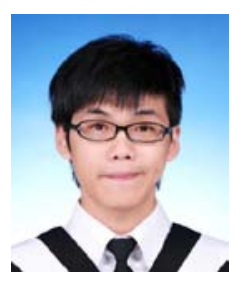

Chih-Chieh Chen is currently working toward his M.S. in Electrical Engineering from the National Yunlin University of Science and Technology, Yunlin, Taiwan (ROC). His current research interests include the design and analysis of power factor correction techniques, switching mode power supplies and soft switching converters. 